\title{
System Modeling and Multi-objective Optimization of Micro-grid Using Bender's Decomposition Algorithm
}

\author{
Mehrdad Rezaei \\ Electrical \& Computer Engineering Department, Semnan University, Semnan, \\ Iran \\ meh.rezaei08@gmail.com
}

\begin{abstract}
This paper presents an operating and cost optimization model for Micro Grid (MG). This model takes into account emission costs of $\mathrm{CO}_{2}, \mathrm{SO}_{2}$ and $\mathrm{NO}_{x}$, together with the operation, maintenance and startup costs. Photovoltaic (PV) arrays, Wind Turbine (WT), Fuel Cell (FC), Micro Turbine (MT) and Diesel Generator (DG) with different capacities are considered in this model. The aim of the optimization is minimizing operation cost according to constraints, supply demand and safety of system. The proposed Bender's Decomposition $(B D)$ is used to optimize the micro grid operation.
\end{abstract}

Keywords: Micro grid, Optimization, Bender's Decomposition.

\section{Introduction}

Developing of Micro Grid is necessary because of the change in regulatory and economic scenarios, problem of energy sources, lack of energy, environment emission problems and so on. The role of MGs is increasing in power system in future [1]. The MG units are chosen to supply load and minimize the cost of the fuel, operation, maintenance and emission level.

First of all an exact model, which can describe accurately all of the aims, is required. Model of system is complex and nonlinear, so optimization tools are needed to reduce the operating costs and minimize the cost of fuel, operation and emission level. Power generation with highly effective performance according to environmental issues has been developed in recent years because global gases emission level is increasing considerably.

One of the best solutions to remedy environmental issues and in the same time supplying electric demand is MGs. Planning of MGs will result in reduced power losses and emission level. Recent researches in MGs reviewed many aspects in different cases, applications and sizes [1], [2].

Communication operating between the power sources to solve the fuel cost optimization problem has been presented in [3]. A different method of modeling MGs which is optimized for cost, operation and reliability constraints has been proposed in [4].The second main goal of this paper is modeling and optimization the problems to have an optimal solution of managing MG.

The aim of the paper is minimization of running costs and supply load demand in the MGs. It can be found that optimization of the system depends on the used model. A proper model can solve the problems and manage the system efficiently. Optimization method used in this paper for modeling the system, incorporates the cost and emissions minimization applied to the MG.

The proposed model not only supplies load demand but also satisfies constraints. The problem has two steps; first step is designing the model of system which is the most important part of the problem solving and the next step is selection of a new algorithm 
and usage of it to optimize model of the MGs by the available resources, considering variables like irradiation, temperature and speed of wind, which are inputs of model.

If photovoltaic and wind outputs don't supply load demand, proposed algorithm will proceed to the next step, and the other alternative is used according to the amount of the load and the cost of resources.

The remaining parts of this paper are as follows: Section 2 and 3 introduce MG architecture and components. Then, introduction and application of the proposed bender's decomposition algorithm for solving the optimization problem of $\mathrm{MG}$ operation is described in section $4,5 \& 6$. Section 7 provides results, and finally, the paper is concluded in Section 8.

\section{System Modeling}

Figure 1 shows the MG structure of the proposed model in this paper. It has feeders which are part of the power distribution systems. The system consists Point of Connection Coupling (PCC). There are sensitive loads connected to feeders $1 \& 2$ which must be supplied all the time. The Feeders include different sources like photovoltaic, fuel cell, wind turbine, diesel generator and micro turbine. Feeder 3 has usual loads which are not sensitive. Fuel cost of WT and PV is free and fuel comes from nature but fuels for DG, FC and MT are not free. PV, WT, DG, MT and FC are sources of system model and each component of MGs is separately modeled according to its characteristics. Manufacturer documents are used for modeling some sources like WT and DG.

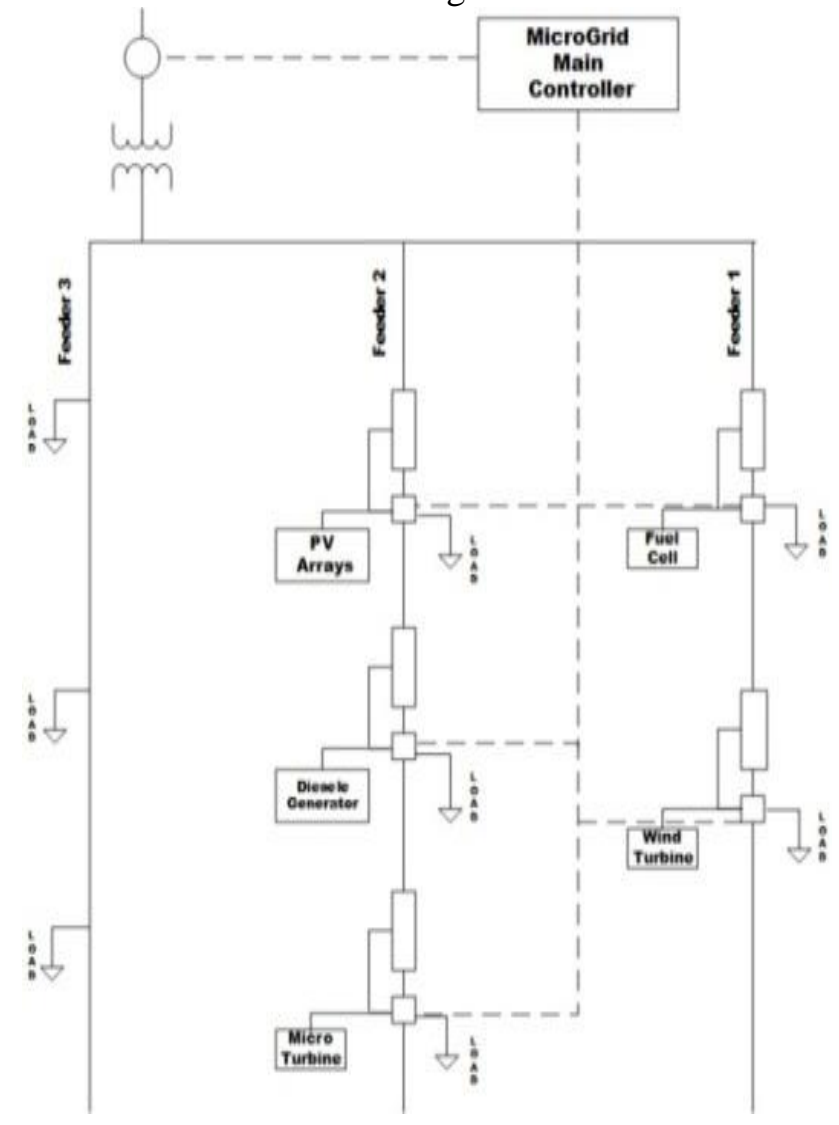

Figure 1. Schematic of the system 


\section{System Architecture Components}

\subsection{Wind Turbine Model}

Wind turbine output depends on wind speed. The characteristic of WT is nonlinear, so sectional modeling of the curve is considered in this paper. Cut in, cut out and rated wind speeds are important points in modeling the system because output power depends on these points. A model which is described by following equations are used to model and estimate the output power of the wind turbine[5] :

$$
\left\{\begin{array}{lr}
P_{W T}=0 & V_{a c}<V_{c i} \\
P_{W T}=a V_{a c}^{2}+b V_{a c}+c & V_{c i} \leq V_{a c}<V_{r} \\
P_{W T, r}=130 & V_{r} \leq V_{a c}>V_{c o}
\end{array}\right.
$$

Where $V_{c i}$, and $V_{c o}$ are cut-in and cut-out wind speed and the rated power. $P_{W T, r}$ is rated power. Furthermore $V_{r}$ and $V_{a c}$ are the rated and actual wind speed.

\subsection{Photovoltaic}

Photovoltaic panel is a new energy source which converts sunlight into electricity. The output power of PV depends on the radiation of sunlight and weather conditions of the location. Sunlight radiation changes all the time so a tracker is needed to achieve the maximum power of PV array. For this purpose, Maximum Power Point Tracking Circuit (MPPTC) is used to achieve the maximum output power of PV panels. The power of the PV panel can be obtained from [6]:

$$
P_{P V}=P_{S T C} \frac{G_{I N G}}{G_{S T C}}\left(1+K\left(T_{c}-T_{r}\right)\right)
$$

Where $\mathrm{P}_{\mathrm{PV}}$ and $\mathrm{P}_{\mathrm{STC}}$ are output power of the module at irradiance and module maximum output power at Standard Test Condition (STC) respectively. $\mathrm{G}_{\mathrm{ING}}$ is incident irradiance, $\mathrm{G}_{\mathrm{STC}}$ is irradiance at STC $1000\left(\mathrm{~W} / \mathrm{m}^{2}\right), \mathrm{k}$ is temperature coefficient of power, $\mathrm{T}_{\mathrm{r}}$ and $\mathrm{T}_{\mathrm{c}}$ are reference and cell temperature respectively.

\subsection{Diesel Generator}

Diesel generators are usually used in MGs as micro sources. New diesel generator (DG) is responsible for peak shaving and supplying load demand. Because of the quick change in output power, DG is an important choice for using in MGs.

The fuel cost depends on its output and it can be described mainly as a function of its power and can be modeled by following formula [7]. The total DG fuel cost is described as:

$C_{D G, i}=\sum_{i=1}^{N} a_{i}+b_{i} P_{D G, i}+c_{i} P_{D G, i}^{2}$

Where $\mathrm{N}$ is the generators numbers. $\mathrm{a}_{\mathrm{i}}, \mathrm{b}_{\mathrm{i}}$ and $\mathrm{c}_{\mathrm{i}}$ are the coefficients of the each generator. $\mathrm{P}_{\mathrm{DG}}$ is the output power $(\mathrm{KW})$ of diesel generator $\mathrm{i}$, and the coefficients are assumed to be known.

\subsection{Fuel Cell Cost}

The efficiency of any fuel cell is the ratio between the electrical power output and the power obtained from input fuel, both of them must be at the same units (W) [8]. The fuel cost for the fuel cell is calculated as:

(4)

$$
C_{F C}=C_{n l} \sum_{j} \frac{P_{j}}{n_{j}}
$$

Where $C_{n l}$ is natural gas price to supply the fuel cell, $P_{J}$ is electrical power produced at interval $J$, and $\eta_{J}$ is cell efficiency at interval $J$. To model the technical performance of a 
fuel cell, a typical efficiency curve is used to develop the cell efficiency as a function of the electrical power and used in equation (4) [8].

\subsection{Micro Turbine Cost}

The economic model is similar to the DG model. Unlike the FC, the efficiency of the MT increases with the increase of the supplied power [9].Due to lack of the detailed information, the curves of the MT are rescaled to be suitable for a unit with less than 4 $\mathrm{kW}$ rating. These curves are used to derive the electrical efficiency as a function of the electrical power to be used in the economic model of the MT.

\section{Bender's Decomposition Algorithm}

Linear Program (LP) called primal problem, it can be formulated in other format which is called dual program. The formulas are as follow:

Main program can be written as below:

where

$$
\begin{gathered}
\text { Minimize } z=c^{T} x+d^{T} y \\
\text { s.t. } \quad A y \geq b \\
x \geq 0, y \quad S
\end{gathered}
$$

A: $m * n$ matrix

E,F: $p^{*} q$ matrix

$\mathrm{x}, \mathrm{c}: \mathrm{q}^{*} \mathrm{n}$ matrix

$\mathrm{y}, \mathrm{d}: \mathrm{n}$ vector

b: $m$ vector

h: q vector

S: subset of $E^{\mathrm{P}}$

The original program can be separated to two parts Master Problem and Sub Problem. Beginning of solving program is MP which written as follow

Primal subproblem are as follow

$$
\begin{array}{cc}
\text { Minimize } \mathrm{z}_{\text {lower }} \\
\text { s.t. } & \mathrm{z}_{\text {lower }} \geq \mathrm{d}^{\mathrm{T}} \mathrm{y} \\
& \mathrm{Ay} \geq \mathrm{b} \\
& \mathrm{y} \in \mathrm{S}
\end{array}
$$

$$
\begin{gathered}
\text { Minimize } c^{T} x \\
\text { s.t. Ex } \geq h-F y \\
x \geq 0
\end{gathered}
$$

Dual of (7) is

$$
\begin{gathered}
\text { Minimize }(h-F \grave{y})^{\mathrm{T}} \mathrm{u} \\
\text { s.t. } \mathrm{E}^{\mathrm{T}} \leq \mathrm{c} \\
\mathrm{u} \geq 0
\end{gathered}
$$

\subsection{Solution Step}

Step 1. Solve Master Problem 1 to achieve first $\mathrm{z}_{\text {lower }}$. It consider whether problem is infeasible or not. if it was feasible P1 will be problem if it was not feasible, $\mathrm{z}_{\text {lower }}$ will be $\infty$ and next step will be started.

Step 2. Solve one of Subproblem 1 or Subproblem 2 (3.6). An upper bound solution of the original problem P1, in Subproblem 2, is $\hat{z}_{\text {upper }}=d^{T} \hat{y}+(h-F \hat{y})^{T} \hat{u}^{p}$ for the 
optimal dual solution. In Subproblem 1, is the upper bound solution of the original problem P1 for $\hat{z}$ upper $=d^{T} \hat{y}+c^{T} \hat{x}$

- If $\left|z_{\text {upper }}-z_{\text {lower }}\right| \leq \varepsilon$ for Problem 1, then stop the process and produce a new constraint $\hat{z}_{\text {upper }} \geq d^{T} \hat{y}+(h-F \hat{y})^{T} \hat{u}^{p}$ (feasibility cut) to solve Master Problem 2 (3.8) and go to step 3.

- If SP2 is unbounded, then introduce a new infeasibility cut for Master Problem 2 (3.8).

$$
\begin{array}{cc} 
& \text { Minimize } 1^{\mathrm{T}} \mathrm{s} \\
\text { s.t. } & \mathrm{Ex}+\mathrm{Is} \geq \mathrm{h}-\mathrm{F} \dot{y} \\
& \mathrm{x} \geq 0, \mathrm{~s} \geq 0
\end{array}
$$

- If SP2 is infeasible, there is no feasible solution. the process will be stop .

Step 3. Solve Master Problem 2 to obtain a new lower bound solution according to y for the original problem 1. In the following Master Problem 2 formulation, we use either the feasibility cut or the infeasibility cut as discussed in Step 2.

$$
\begin{gathered}
\text { Minimize } \mathrm{z}_{\text {lower }} \\
\text { s.t. } \quad \mathrm{Ay} \geq \mathrm{b} \\
\hat{z_{\text {upper }}=} d^{T} \hat{y}+(h-F \hat{y})^{T} u_{i}{ }^{p}, \mathrm{i}=1, \ldots, \mathrm{n}_{\mathrm{p}} \\
(\mathrm{h}-\mathrm{Fy})^{\mathrm{T}} \mathrm{u}_{\mathrm{i}}^{\mathrm{r}} \leq 0, \quad \mathrm{i}=1, \ldots, \mathrm{n}_{\mathrm{r}}
\end{gathered}
$$

Figure 2. describes solution steps of benders decomposition algorithm in order to solve the problem.

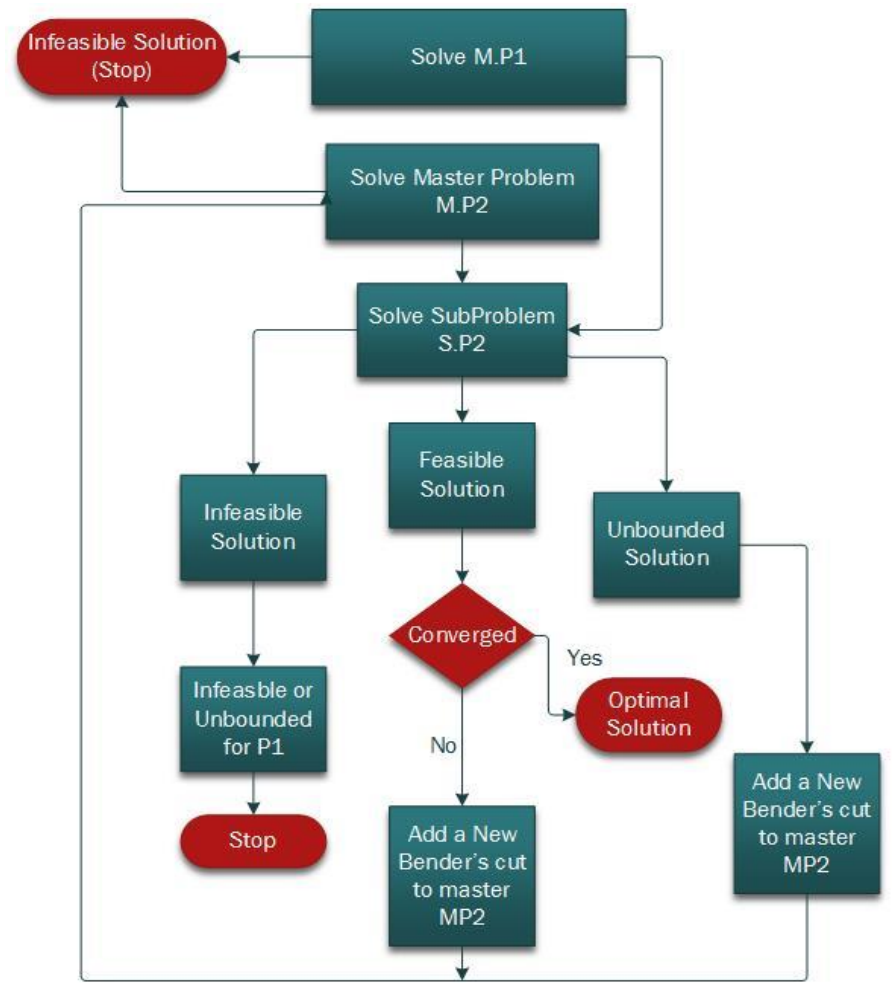

Figure 2. Algorithm Flowchart 


\section{Proposed Objective Function}

This section describes the proposed objective cost function for the MG. The model considers environmental costs and minimizes the emissions of oxides of nitrogen $\left(\mathrm{NO}_{\mathrm{x}}\right)$, sulfur oxides $\left(\mathrm{SO}_{2}\right)$, and carbon oxides $\left(\mathrm{CO}_{2}\right)$. Also this function minimizes the operating costs in $\$ / h$. In proposed model the power can be purchased or sold in different condition. When generation of power is insufficient to supply the load, it can be purchased. On the other hand, when the output power is more than the needed power, it can be sold. The proposed model is:

$$
C F(P)=\sum_{i=1}^{N}\left(C_{i} * F_{i}\left(P_{i}\right)+O M_{i}\left(P_{i}\right)+S T C_{i} \alpha_{i}+C P E_{i}-C S E_{i}\right)+\sum_{i=1}^{N} \sum_{j=1}^{M} \beta_{j} E F_{i j} P_{i}
$$

where:

$C_{i} \quad$ Fuel costs of generating unit i $\$ / \mathrm{L}$ and $\$ / \mathrm{kW}$ for the diesel and the natural gas respectively,

$F_{i} \quad$ Fuel consumption rate of generator unit i $(\mathrm{L} / \mathrm{h})$ for diesel generator, and $\mathrm{kW} / \mathrm{h}$ for the $\mathrm{FC}$ and MT,

$O M_{i}$ Operation and maintenance cost of a generating unit i (\$/h), STC $C_{i}$ Startup cost of unit i, $C P E_{i}$ Cost of purchased electricity $(\$ / \mathrm{h}), C S E_{i}$ Cost of sold electricity $(\$ / \mathrm{h}), \beta_{j}$ Externality costs of emission $\mathrm{j}(\$ / \mathrm{lb}), E F_{i k}$ Emission factor of generating unit $\mathrm{i}$ and emission $\mathrm{j}$ (lb/MWh),

$N$ number units , $M$ Emission types $\left(\mathrm{NO}_{\mathrm{x}}\right.$ or $\mathrm{CO}_{2}$ or $\left.\mathrm{SO}_{2}\right)$.

The operating and maintenance cost of the generating unit i $\left(O M_{i}\right)$ is assumed to be proportional to the produced energy, $K_{O M}$ is the proportional constant [8].

$O M_{i}=K_{O M} \sum_{i=1}^{N} P_{i}$

The values of the $\mathrm{KOM}$ for different generation units are as follows: $\mathrm{K}_{\mathrm{OM}}$ (DG) = $0.01257, \mathrm{~K}_{\mathrm{OM}}(\mathrm{FC})=0.004189, \mathrm{~K}_{\mathrm{OM}}(\mathrm{MT})=0.005877 \$ / \mathrm{kWh}$

The startup cost is as below [10]:

$$
S C_{t}=\sum_{k=1}^{N D+N T}\left[h s t_{k}+c s t_{k}\left[1-\exp \left(\frac{-T F_{t}^{k}}{C L T^{k}}\right)\right]\right]
$$

Where ND and NT are number of diesel generators and micro turbines respectively; $h s t_{k}, c s t_{k}$ and $C L T^{k}$ are hot start-up cost, cold start-up cost and unit cooling time constant for the generator $k$, respectively; $T F_{t}^{k}$ is the time that the generator $k$ has been off up to time $t$. Shutdown cost is not considered in proposed and WT and PV are considered to be free and have no fuel cost.

\section{Objective Constraints:}

The output power generated by units must supply the total load demand:

$\sum_{i=1}^{N} P_{i} I_{t}=P_{L}-P_{P V}-P_{W}$

Where $\mathrm{P}_{\mathrm{i}}, \mathrm{P}_{\mathrm{L}}, \mathrm{P}_{\mathrm{PV}}, \mathrm{P}_{\mathrm{WT}}$ are generated power of each unit $[\mathrm{kW}]$, the power demanded by the load $[\mathrm{kW}]$,the generated power of the photovoltaic $[\mathrm{kW}]$, the generated power of the wind turbine $[\mathrm{kW}]$ respectively.

Generation capacity constraints: For stable operation, real power output of each generator must be between lower and upper limits of generated power: 
$P_{i}^{\text {min }} I_{t}<P_{i}<P_{i}^{\max } I_{t} ; \quad \mathrm{i}=1, \ldots, \mathrm{N}$

(15)

Where $P_{i}^{\min }$ and $P_{i}^{\max }$ are minimum and maximum generated power of unit i.

\section{Application of the Benders decomposition for solving optimization problem of MG operation}

To apply Benders decomposition to SCUC, The main cost function was written as a standard Benders decomposition formula.

In this paper, unit commitment is solved by two GAs, the first GA is used to solve the unit scheduled problem and the second GA solve economic dispatch problem.

\subsection{Unit Scheduled Problem}

A GA is used to solve unit scheduled problem, if load increases, units by lower operating cost are in priority to be used and if load decreases units by higher operating cost are in priority to turn off. Finally list of unit's status in 24 hours is output of first step of unit commitment.

\subsection{Economic Dispatch Problem}

The proposed bender's decomposition is used in this section, first of all MP and SP are defined to solve the problem. Next step is as flowchart which is shown in Figure 2. The following is basic rule of using units.

- Output power of WT depends on the wind speed according to equation (1).

- Output power of PV depends on the temperature and the solar radiation according to equation (2).

- Because PV and wind turbine output powers are free and come from nature, they are assumed to be negative loads in the formula. If outputs of PV and WT can't supply load demand algorithm will go next steps and uses the other sources according to objective function.

- Selection of the other sources depends on fuel cost of sources and aim of algorithm is to minimizing the cost of the generation.

All the formulas can be mathematically written as follows:

$$
\begin{array}{r}
\min _{\mathrm{P}_{\mathrm{i}} \in \mathrm{R}^{\mathrm{n}} \mathrm{CF}\left(\mathrm{P}_{\mathrm{i}}\right)} \\
\text { subject to: } \\
\mathrm{g}_{\mathrm{i}}=0 \\
\mathrm{~h}_{\mathrm{i}} \geq 0
\end{array}
$$

$\mathrm{P}_{\mathrm{i}}$ is vector of generated powers, $\mathrm{CF}\left(\mathrm{P}_{\mathrm{i}}\right)$ is calculated cost function according to equation (11), $g_{i}$ is equality constraint according to the equation (14) and finally $h_{i}$ inequality constraint according to the equation (15).

\section{Numerical Result and Discussion}

Wind turbine and photovoltaic output power is calculated by real data. Wind speed and temperature are inputs of the model. From output power obtained of PV and WT, it is concluded that other sources are needed to serve loads. The algorithm goes to next step; the needed power to cover the load is calculated. Figure 3. and Figure 4. show output powers of MG calculated by the algorithm. Table 1. shows 24 hours load demand minus output powers of WT and PV which are applied to the described model. The constants values of DGs and MT are used in the model are shown in Table 2. [11],[12] and emission constants are tabulated in Table 3[13]. 


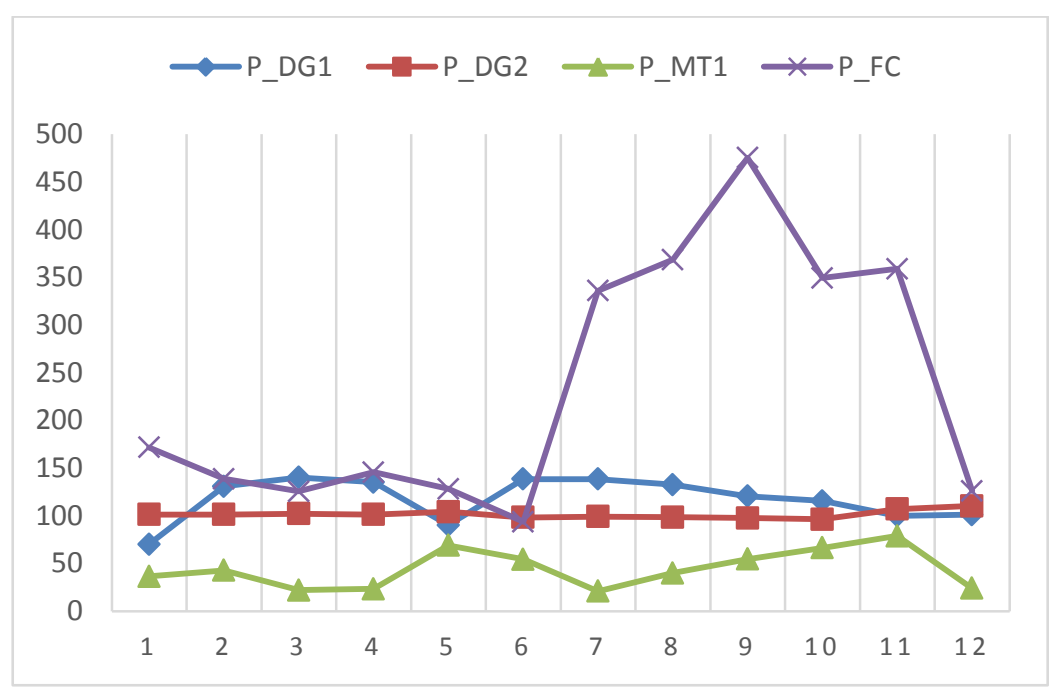

Figure 3. Output of DG1, DG2, MT1 and FC

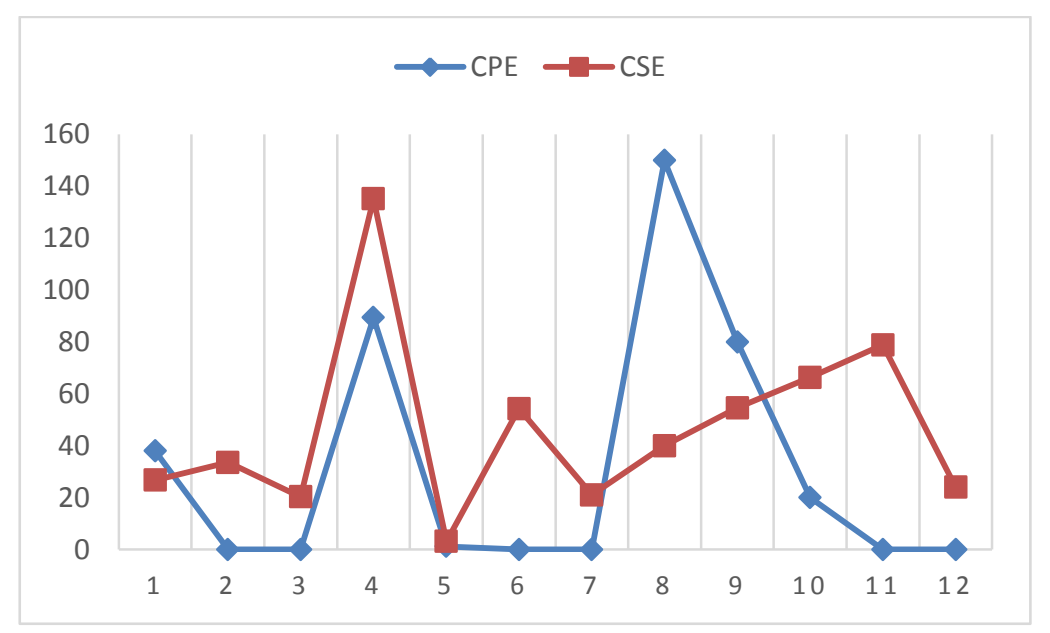

Figure 3. Output of CPE, CSE

Table1. Hourly Load

\begin{tabular}{|c|c|c|c|c|c|}
\hline Hour & $\begin{array}{c}\text { Load } \\
(\mathrm{KW})\end{array}$ & $\begin{array}{c}\text { Load-P } \\
\mathrm{P}_{\mathrm{WT}}(\mathrm{KW})\end{array}$ & Hour & $\begin{array}{c}\text { Load } \\
(\mathrm{KW})\end{array}$ & $\begin{array}{c}\text { Load-P }_{\mathrm{PV}^{-}} \\
\mathrm{P}_{\mathrm{WT}}(\mathrm{KW})\end{array}$ \\
\hline 1 & 430 & 390 & 13 & 790 & 770 \\
\hline 2 & 420 & 380 & 14 & 805 & 790 \\
\hline 3 & 400 & 370 & 15 & 812 & 800 \\
\hline 4 & 380 & 360 & 16 & 910 & 900 \\
\hline 5 & 430 & 390 & 17 & 1000 & 950 \\
\hline 6 & 445 & 420 & 18 & 1130 & 1100 \\
\hline 7 & 575 & 550 & 19 & 1430 & 1390 \\
\hline 8 & 763 & 750 & 20 & 1460 & 1400 \\
\hline 9 & 828 & 800 & 21 & 1200 & 1150 \\
\hline 10 & 640 & 630 & 22 & 1220 & 1180 \\
\hline 11 & 650 & 640 & 23 & 830 & 800 \\
\hline 12 & 655 & 650 & 24 & 540 & 500 \\
\hline
\end{tabular}


Table 2. Parameters OF DGs AND MT

\begin{tabular}{|c|c|c|c|}
\hline$G E N$ & $D G_{I}$ & $D G_{2}$ & $M T$ \\
\hline $\begin{array}{l}P_{\max }^{G E N} \\
(\boldsymbol{K} \boldsymbol{W})\end{array}$ & 200 & 500 & 150 \\
\hline $\begin{array}{l}P_{\min }^{G E N} \\
(\boldsymbol{K} \boldsymbol{W})\end{array}$ & 20 & 50 & 16 \\
\hline $\begin{array}{c}s t_{G E N} \\
(\$)\end{array}$ & 0.0075 & 0.0125 & 0.0102 \\
\hline $\begin{array}{c}c s t_{G E N} \\
(\$)\end{array}$ & 0.0175 & 0.0225 & 0.0202 \\
\hline $\begin{array}{c}c_{\text {clt }} \\
(\$)\end{array}$ & 0.0183 & 0.0183 & 0.1444 \\
\hline$A$ & $6.098215 \mathrm{E}+00$ & $1.481760 \mathrm{E}+01$ & $5.768000 \mathrm{E}-01$ \\
\hline$B$ & $1.858326 \mathrm{E}-01$ & 2.2399 34E-01 & $5.778300 \mathrm{E}+01$ \\
\hline $\mathrm{C}$ & $\begin{array}{c}-1.021590 \mathrm{E}- \\
04\end{array}$ & $\begin{array}{c}-8.189469 \mathrm{E}- \\
05\end{array}$ & $1.330915 \mathrm{E}+02$ \\
\hline
\end{tabular}

Table 3. Emission Factors

\begin{tabular}{|l|l|l|l|l|}
\hline & $\alpha_{j}(\$ / \mathrm{Ib})$ & $\begin{array}{l}E F_{i k} \text { of } D G \\
(\mathrm{l} / \mathrm{MWh})\end{array}$ & $\begin{array}{l}E F_{i k} \text { of } F C \\
(\mathrm{l} / \mathrm{mWh})\end{array}$ & $\begin{array}{l}E F_{i k} \quad \text { of } \\
M T \\
(\mathrm{~b} / \mathrm{MWh})\end{array}$ \\
\hline $\mathrm{NO}_{\mathrm{x}}$ & 4.2 & 21.8 & 0.03 & 0.44 \\
\hline $\mathrm{SO}_{2}$ & 0.99 & 0.454 & 0.006 & 0.008 \\
\hline $\mathrm{CO}_{2}$ & 0.014 & 1.432 & 1.078 & 1.596 \\
\hline
\end{tabular}

Comparison of results of proposed benders algorithm for defined MG operation problem is tabulated in Table IV. Lindoglobal, counne and Antigone aregams solvers which are used to solve problems in GAMS software. Comparison shows the proposed Benders algorithm not only reduces computation time but also has lower cost function so application of algorithm is sufficient.

Table 4. Comparison Of Result

\begin{tabular}{|c|c|c|}
\hline Method & $\begin{array}{c}\text { Ave. of } \\
\text { Computation } \\
\text { time(min) }\end{array}$ & Ave. objective (\$) \\
\hline $\begin{array}{c}\text { Bender's } \\
\text { Algorithm }\end{array}$ & $\mathbf{5 5 . 0 6}$ & $\mathbf{8 3 0 . 3 4 7}$ \\
\hline LINDOGLOBAL & 180.76 & 838.165 \\
\hline COUENNE & 208.4899 & 846.48682 \\
\hline ANTIGONE & 215.3307 & 2437.8505 \\
\hline
\end{tabular}

\section{Conclusion}

A model is designed to calculate the best optimum of a microgrid according to load demand and environmental issues. MG model includes a fuel cell, a diesel generator, a micro turbine, photovoltaic arrays, and a wind generator. Constraints are considered in the model. It can be obtained from results; the proposed algorithm works efficiency to achieve best optimized results. Generation of each generators is obtained from algorithm and is used to planning MG. The results depend on different variables such as weather condition, wind speed, sun radiation, emission and maintenance costs and power demand. 


\section{References}

[1] M. Liserre, T. Sauter and J. Y. Hung, "Future energy systems, integratingrenewable energy sources into the smart power grid through industrialelectronics", IEEE Ind. Electron. Mag., vol. 4, no. 1, (2010), pp. $18-37$.

[2] H.-M. Kim and T. Kinoshita, "A Multiagent System for Microgrid Operation in the GridinterconnectedMode", Journal of Electrical Engineering \& Technology, vol. 5, no. 2, (2010), pp. 246-254.

[3] R. Lasseter, "MicroGrids", IEEE Power Engineering Society Winter Meeting, (2002), pp. 305-308.

[4] S. Meliopoulos, "Challenges in Simulation and Design of Grids", Proceedings of the IEEE/PES Winter Meeting, (2002).

[5] C. A. Hernandez-Aramburo, T. C. Green and N. Mugniot, "Fuel Consumption Minimization of a Microgrid", IEEE Transactions OnIndustry Applications, vol. 41, no. 3, (2005), pp. 673-681.

[6] S. B. Patra, J. Mitra and S. J. Ranade, "Microgrid architecture: A Reliability Constraind Approach", IPowerEngineeringSociety General Meeting, IEEE, vol. 12-16, vol. 3, (2005), pp. $2372-2377$.

[7] R. Chedid, H. Akiki and S. Rahman, "A decision support technique for the design of hybrid solar- wind power systems", IEEE Transaction on Energy Conversion, vol. 13, no. 1, (1998), pp. 76-83.

[8] F. Lasnier and T.G. Ang, "Photovoltaic Engineering Handbook", IOP Publishing Ltd., (1990).

[9] A. J. Wood and B. F. Wollenberg, "Power Generation, Operation and Control", Book., John Wiley \&Sons, Ltd, (1996).

[10] A. M. Azmy and I. Erlich, "Online Optimal Management of PEM Fuel Cells Using Neural Networks", IEEE Transactions on Power Delivery, vol. 29, no. 2, (2005), pp. 1051-1058.

[11] S. Campanari and E. Macchi, "Technical and Tariff Scenarios effect on MicroturbineTrigenerativeApplications", Journal of Engineering for GasTurbines and Power, vol. 126, (2004), pp. 581-589.

[12] C. S. Wang, B. Yu, J. Xiao and L. Guo, "Multi-scenario, multi-objective optimization of grid-parallel Microgrid", Deregulation and Restructuring and Power Technologies (DRPT), (2011), pp. 1638-1646.

[13] A. K. Basu, A. Bhattacharya, S. Chowdhury and S. P. Chowdhury, "Planned Scheduling for Economic Power Sharing in a CHP-Based Micro-Grid”, IEEE Transactions on Power Systems, vol. 27, no. 1, (2012), pp. 30-38.

[14] "[Online].Available:www.cumminspower.com/Commercial1/Diesel/S-1215.pdf".

[15] W. Morgantown, "Emission for new DG technologies", The Regulatory Assistance Project, [online], Available, http:// www.raponline.org/projdocs/dremsrul/collfile/dgemissionmay2001.pdf, (2001).

\section{Author}

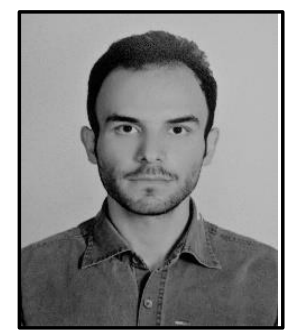

Mehrdad Rezaei, He received his BSc degree in Power Engineering from Shahid Beheshti University, Iran in 2010. His MSc is in power engineering from Semnan University. His interests are in smart grids, renewable energies and power system. 